\title{
Numerical Analyses of the Effect of Boiler Design on the Performance of a Liquid Fuelled Boiler
}

\author{
Bilal Sungur, Bahattin Topaloglu, Hakan Ozcan \\ Mechanical Engineering Department, Ondokuz Mayis University \\ Samsun, Turkey \\ bilal.sungur@omu.edu.tr; btopal@omu.edu.tr; ozcanh@omu.edu.tr
}

\begin{abstract}
In this study, flame structures, velocity distributions and exhaust gas temperatures were investigated numerically for four different boiler design of a liquid fuelled boiler. Keeping the outer dimensions constant at boiler design, two parameters were investigated: the effect of the smoke tube diameter and numbers and the structure of the flame tube. Calculations were performed at two dimensional axisymmetric conditions and Fluent software was used as the computational fluid dynamics program. In all calculations, the standard k- $\varepsilon$ model was used for modeling the turbulent flow, the species transport model was used for modeling the combustion, and the pressurized swirl atomizer was used for modeling the injection. The calculations showed that decreasing the smoke tube diameters by doubling their numbers the exhaust gas temperatures decreased and the efficiency increased importantly. But by increasing the smoke tube numbers from two to three the decrease in exhaust gas temperature is negligibly small. Also, narrowing the flame tube and changing the flow of the combustion gases in flame tube have positive effect on the heat transfer.
\end{abstract}

Keywords: Combustion, Numerical modelling, Diffusion flame, Boiler design

\section{Introduction}

The demand of energy is creasing day by day with the growing population and developing technology. Generally petroleum-based fuels used for producing energy but these fuels have harmful effects on environment and also these sources depleted day by day. To solve this problem, researchers have turned to different quest. In this context, the importance of the using energy efficiently and relevance in alternative and renewable fuels has increased. Boilers are defined as an arrangement of vessels and tubes with a furnace (heat source), in which water or other fluid is heated by combustion of fuel and generally used for heating or power applications. The heat of combustion is transferred to the fluid in the boiler and then this fluid transferred to the desired area. During the liquid fuel combustion, the flame is yellow-red colour because of the particle formation. Due to the long time necessary for combustion, the flame will be long. In order to be good and efficient combustion, heat and mass transfer must be good and so the total contact area of droplets must be as large as possible. The energy efficiency of boilers depends on fuel consumption, fuel lower heating value and the amount of energy (after fuel combustion) transferred to the fluid. However, flue gas emissions depend on combustion quality, flame and smoke tube positions, and passes in short boiler design, burner design, and the amount of contaminants in the fuel.

During combustion the mass, momentum and energy transfer occurs at the same time and solving these governing equations without computer programs almost impossible. In general, partial differential equations like continuity, momentum, energy and species transport can be solved with only numerical methods. There is a lot of computational fluid dynamics (CFD) software in market and FLUENT software is one of them.

In liquid fuel combustion, the fuel comes into droplets firstly, and then gasification and vaporization occurs. Thus, fuel is sprayed by the pump into combustion air delivered by a fan or compressor. In some systems where fuel has a high viscosity, the fuel pre-heating may be needed. After these processes air-fuel mixture is ignited with an igniter (for example formation of sparks between the electrodes under high voltage). To get a good mixing of the fuel with air, various apparatuses were used like air rotator turbulators. These apparatuses also help to stabilize of the flame. There are different burner types according to the purpose. Among these, high-pressurized fuel burners, air or steam blast burners, and rotary burners are the most known. 
Cundari et al. [1] investigated the diesel and biodiesel blends (up to $25 \%$ ) combustion experimentally and numerically. They used RNG k- $\varepsilon$ turbulence model, and species transport-eddy dissipation combustion model in calculations. Experimental results showed that in the higher blend of biodiesel (B25), the temperature of combustion chamber was less than diesel. They said that the pattern of temperature distribution was almost equal with the use of B0 and B25. Mondal and Roy [2] investigated the burning characteristics of liquid toluene droplets for different combustor geometries and droplet sizes. They used non-adiabatic presumed probability density function model in combustion calculations. They reported that droplet size, inlet pattern and oxidizer temperature have an important effect on combustion temperature distribution and pollutant formation. Ing et al. [3], researched the spray characteristics of biodiesel - diesel blends in various blend ratios, and comparised these mixture ratios with pure diesel. They used Fluent software in numerical calculations. As turbulence model k- $\varepsilon$ model was used and they indicated that $\mathrm{k}-\varepsilon$ model predicted the spray characteristics of all biodiesel blends successfully. Saario et al. [4] studied the heavy fuel oil combustion in the furnace experimentally and numerically. In numerical calculations, they used Fluent software and they tried standard k- $\varepsilon$ and Reynolds Stress Model (RSM) separately as turbulence model. As a combustion model, mixture fraction and the probability density function approach were used. They said that predicted gas concentrations were in satisfactory agreement with experimental results, but they found that there were conflicting results near the burner and near the furnace axis. $\mathrm{Hu}$ [5] investigated the liquid fuel combustion at different fluid spray burners, experimentally and numerically. He reported that numerical results provided a good agreement with experimental results. In the study of Hosseini et al. [6], combustion and emission characteristics of diesel-biodiesel fuel blends at a liquid fuelled boiler were investigated. They observed that diesel emitted more $\mathrm{CO}, \mathrm{CO}_{2}$ and particulate matter than biodiesel, but less $\mathrm{NO}_{\mathrm{x}}$. They stated that the use of biodiesel could be useful in industrial processes.

To improve the thermal efficiency, the sensible heat of flue gases must be diminished, accordingly the exhaust gas temperature must be decreased. In this study, flame structures, velocity distributions and exhaust gas temperatures were investigated at two dimensional axisymmetric conditions with different boiler design of a liquid fuelled boiler. In calculations two parameters were investigated: the effect of the smoke tube diameters and numbers and the structure of the flame tube.

\section{Materials and Methods}

Developments on the technology and computer science have increased the importance of Computational Fluid Dynamics software, usually called as CFD, in last years. Using physical experiments to get essential engineering data for design can be expensive and time consuming. CFD simulations are relatively inexpensive and can be executed in a short period of time. In practice, some computational fluid dynamics software is available and FLUENT software is one of them. Fluent can solve many different processes such as heat transfer, fluid motion, particle motion, droplet motion and combustion with finite volume method [7].

Modeling of the movement of the gas phase was made by Eulerian perspective to solve the mass, momentum, and energy conservation equations for scalar variables. These differential equations were solved using appropriate boundary conditions on the problem. The general form of conservation equations are expressed as follows:

$$
\frac{\partial}{\partial t}(\rho \phi)+\operatorname{div}\left(\rho v \phi-\Gamma_{\phi} \operatorname{grad} \phi\right)=S_{\phi}
$$

In this equation, $\phi$ is the dependent variable, $\Gamma_{\phi}$ is transport coefficient of $\phi$, and $S_{\phi}$ is the source term of the transport equation.

Lagrange perspective was made for modeling of the movement of the liquid phase. Fuel is sprayed by the pump into combustion air delivered by a fan or compressor. As a result of spraying a droplet spectrum with different velocity and droplet size are occurred. Due to different initial values, droplets track on different trajectories, heat and evaporate with different velocities, then mixed with air and burn. The motion of the gas and liquid phases are taken into account with successive iterations.

For modeling combustion at Fluent software its necessary to choose a combustion model, turbulence model and radiation model. In this study, species transport- eddy dissipation model was used as combustion model, standart k- $\varepsilon$ model was used as turbulence model, and P1 approach model was used as radiation model. Liquid fuel was injected with pressure from the centre of the burner. Calculations were carried out for four different situations. These geometries were given in 
Figure 1. Only one half of the boiler geometries are shown because of the axial symmetry. The Geometry 1 is the basic geometry, which is a reversal flame smoke tube boiler. The combustion chamber has a length of $60 \mathrm{~cm}$ and an inner diameter of $34 \mathrm{~cm}$. The smoke tubes surrounded the combustion chamber circularly. The length and the inner diameter of the smoke tubes are $70 \mathrm{~cm}$ and $7 \mathrm{~cm}$, respectively. The flame formed in the combustion chamber has three passes. The first pass is the flame itself, the second is the pass from back of the combustion chamber to the front (reverse flame) and the flue gas through the smoke tubes is the last pass. The heat due to the fuel combustion is transferred to the water in the boiler. The other geometries are formed by keeping the outer dimensions of the basic geometry constant. Geometry 2 and Geometry 3 are formed by doubling and tripling the smoke tube number, respectively. Geometry 4 is formed by narrowing the flame tube diameter and adding a further smoke tube which act now as second pass. Thermal power of the boilers was adjusted to $30 \mathrm{~kW}$ and injector spray pressure was adjusted to 6 bars, respectively. Pressurized swirl atomizer injection model was used as injection type, injection half angle was given $30^{\circ}$ and injector diameter was given $0.4 \mathrm{~mm} . \mathrm{C} 10 \mathrm{H} 22 \mathrm{fuel}$ was accepted as diesel fuel and the fuel viscosity was entered $0.0024 \mathrm{~kg} / \mathrm{m} \mathrm{s}$. All four cases have the same air/fuel conditions, only their geometries were changed in calculations.
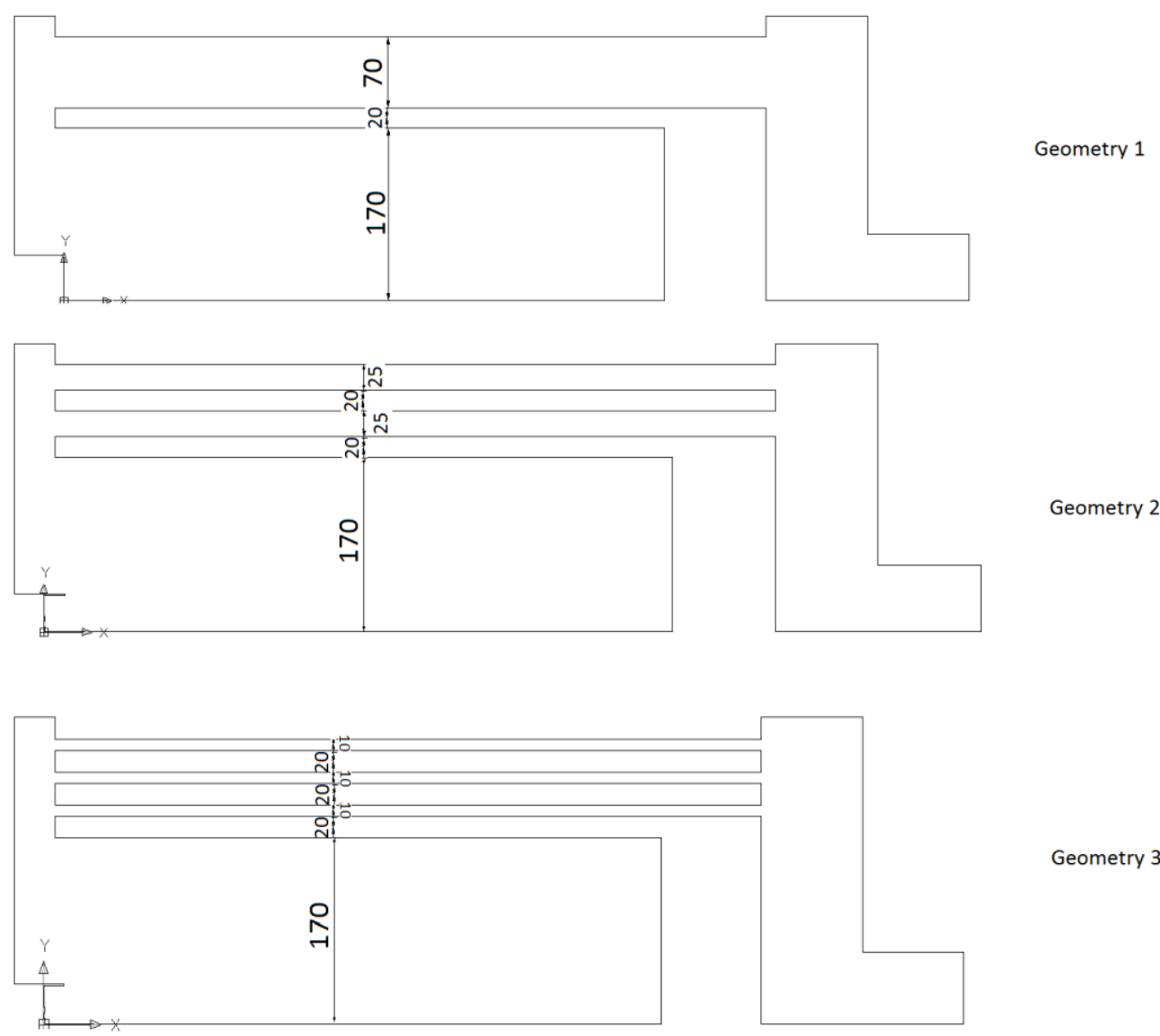

Geometry 3

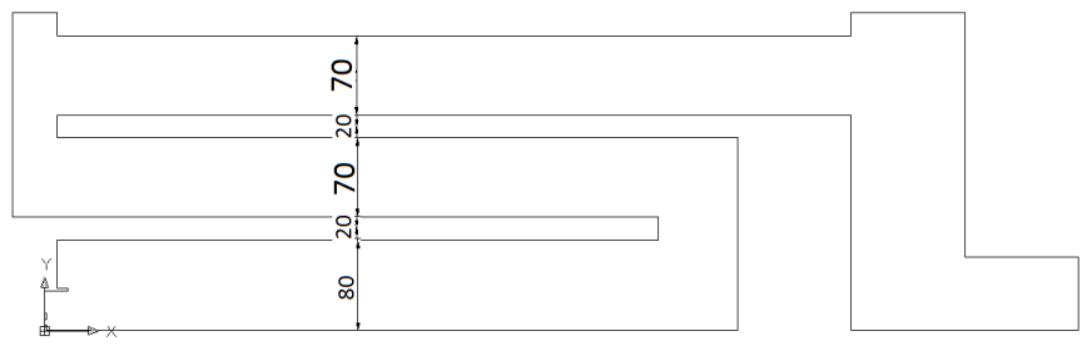

Geometry 4

Fig. 1: Dimensions and types of the boiler geometries. 
The mesh structure for Geometry 1 which was used in this study was given in Figure 2. This mesh has a total of approximately 180,000 cells. Also, more grid structures were tested to see the grid's effect on the solution. Very fine grid having constant edge lengths of $0.5 \mathrm{~mm}$ and coarser grid having constant edge lengths of $2 \mathrm{~mm}$ with 800,000 and 50,000 meshes, respectively, were also used for calculations. However, in these calculations with more grids, there were no meaningful changes in the results; consequently, all calculations were performed with the grid with 180,000 meshes. In other designs similar meshes were created. Surfaces in contact with water were defined as the wall with constant wall temperature of $353 \mathrm{~K}$. Exit zone was defined by pressure outlet, and air inlet was defined by velocity inlet.

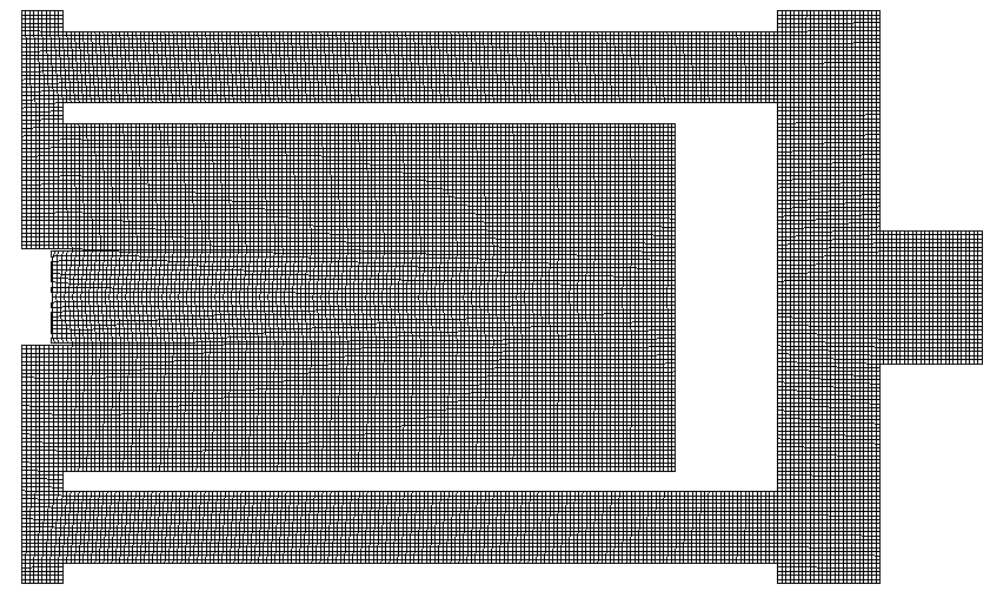

Fig. 2: The mesh structure of the Geometry 1.

\section{Results and Discussions}

In liquid fuel combustion fuel is sprayed by the pump into combustion air. In consequence of spraying a droplet spectrum with different velocity and droplet size are occurred. Due to different initial values, droplets track on different trajectories, heat and evaporate with different velocities, then mixed with air and burn. Figure 3 represents the droplet trajectories in Geometry 1. As shown in this figure, the maximum droplet diameter was around $80 \mu \mathrm{m}$ and the minimum droplet diameter was around $3 \mu \mathrm{m}$. The smaller droplets warmed up, evaporated and burned very fast. The bigger droplets needed more time for the same processes. Only the Geometry 1 was shown because the droplets behaviour was similar in all other geometries.

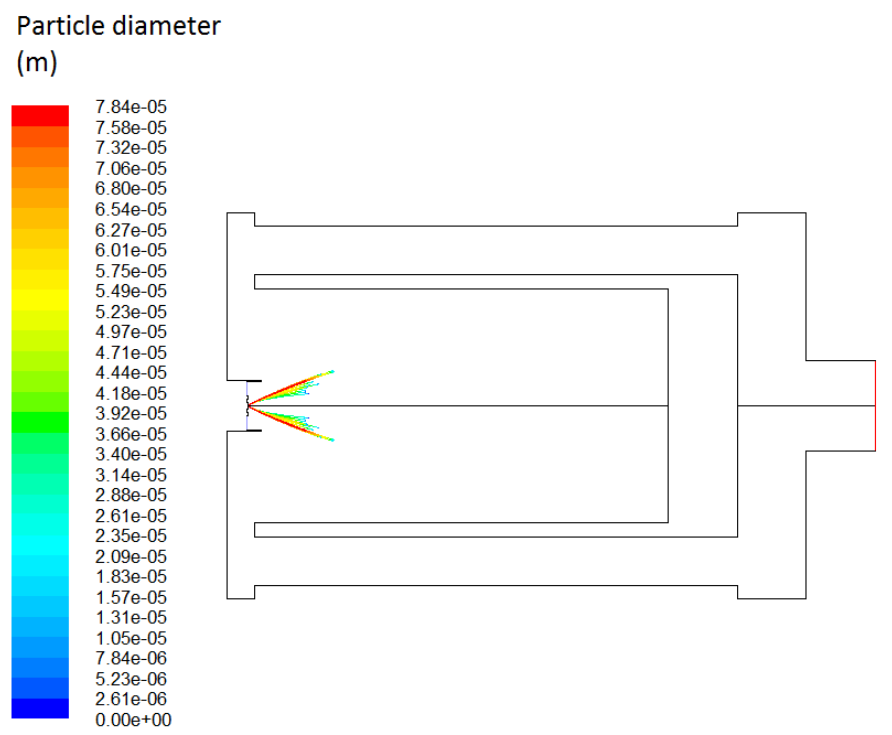

Fig. 3: Droplet trajectories in Geometry 1. 
Figure 4 shows the temperature contours in the boiler for different geometries. As shown in this figure, in all cases the highest temperatures occurred in inlet of the combustion chamber and the temperatures decreased towards the chimney because of the heat transfer from the flame and smoke tubes to the water. As shown in Figure 4, the maximum flame temperatures occurred in Geometry 4 with nearly $1600 \mathrm{~K}$. Geometry 1, Geometry 2 and Geometry 3 had almost similar flame images and the maximum flame temperatures in these geometries were nearly $1400 \mathrm{~K}$.
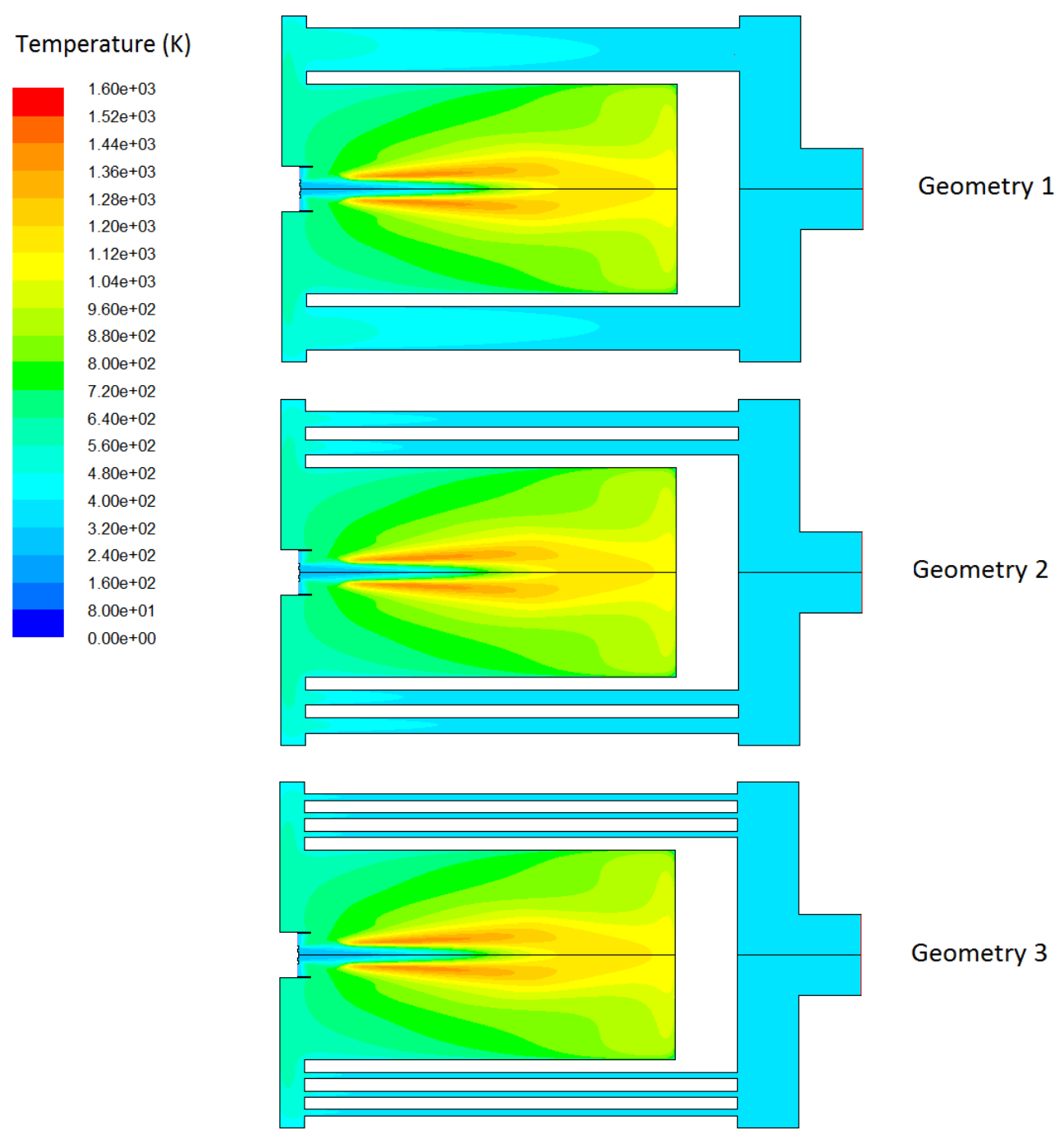

Geometry 3

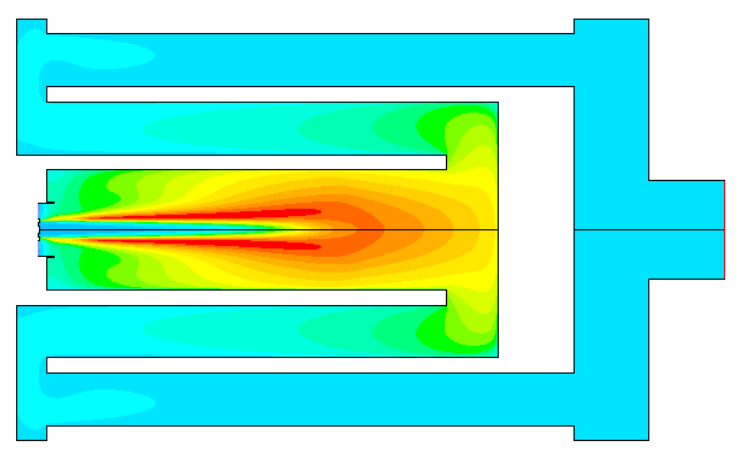

Geometry 4

Fig. 4: The temperature contours in the boiler for different geometries. 
In Figure 5, stream functions were given for different boiler geometries. As can be seen from this figure, flow progressed along the flame tube, turned back from there and directed to one smoke tube in Geometry 1, two smoke tubes in Geometry 2 and three smoke tubes in Geometry 3. In Geometry 4 flow progressed along the narrowed flame tube and then turned back from there and directed to the second pass, and turned from there to the third pass.
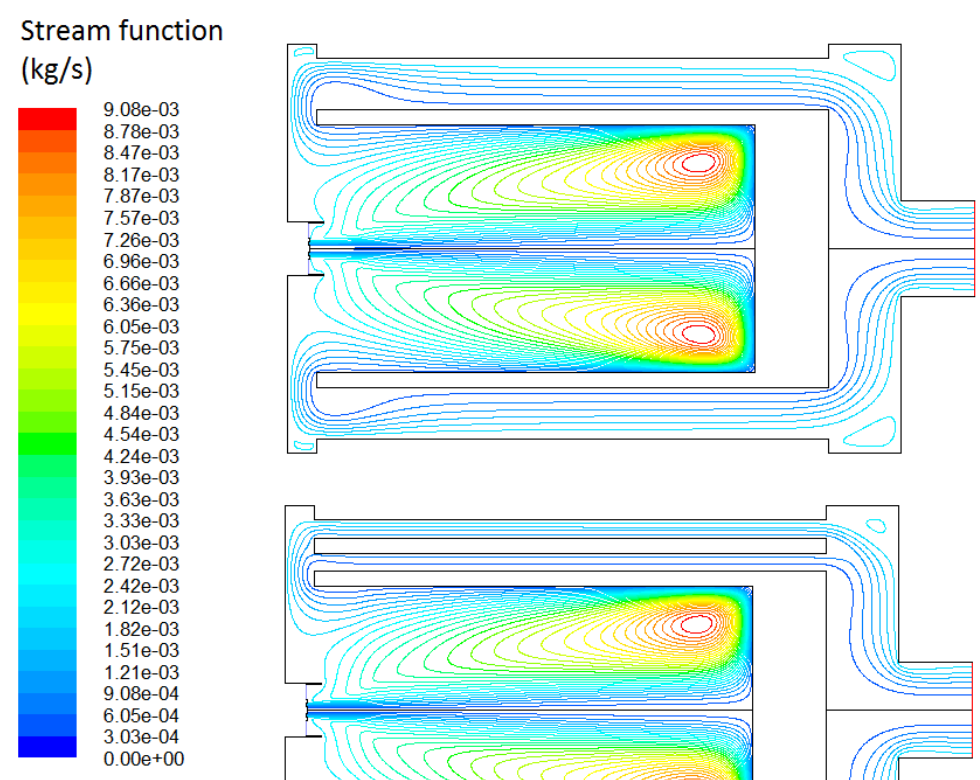

Geometry 1

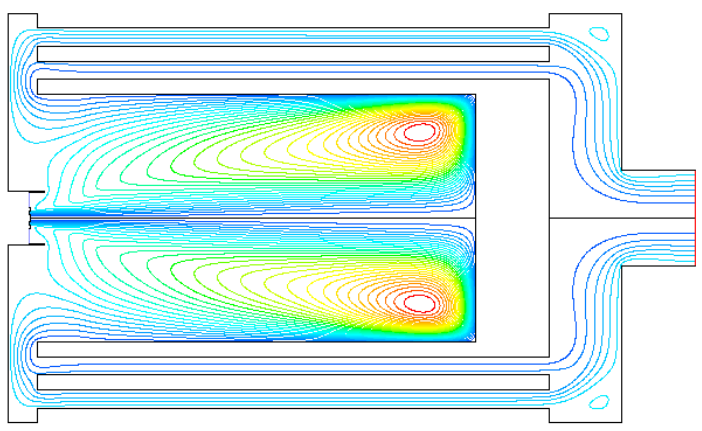

Geometry 2

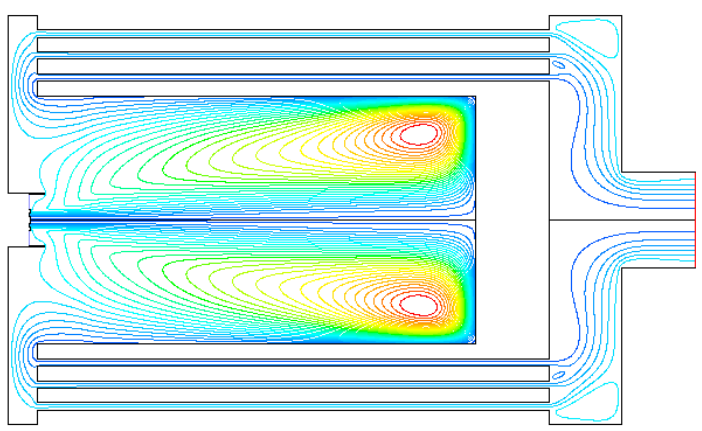

Geometry 3

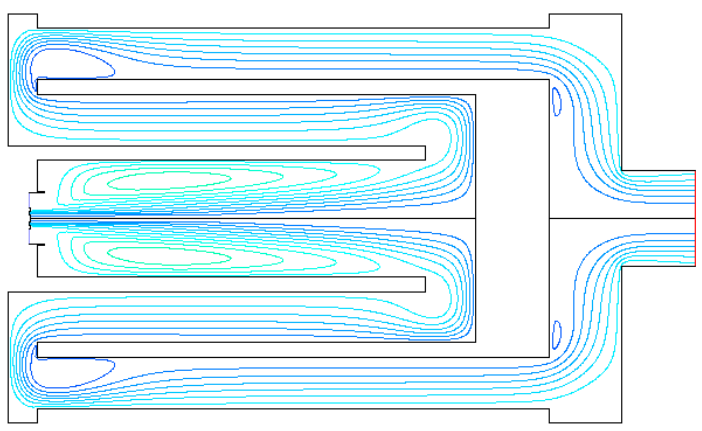

Geometry 4

Fig. 5: Stream function contours in the boiler for different geometries. 
Exhaust gas temperatures for all geometries were given in Figure 6 for comparison. Exhaust gas temperatures decreased almost $18 \mathrm{~K}$ (from $372 \mathrm{~K}$ to $354 \mathrm{~K}$ ) from Geometry 1 (one smoke tube pass) to Geometry 2 (two smoke tube pass). Increasing the passes of smoke tube from two to three smoke tube, slightly decreased (nearly $2 \mathrm{~K}$ ) the exhaust gas temperatures. In this context it can be said that the Geometry 3 has the best performance and Geometry 1 has the worst performance among all these geometries.

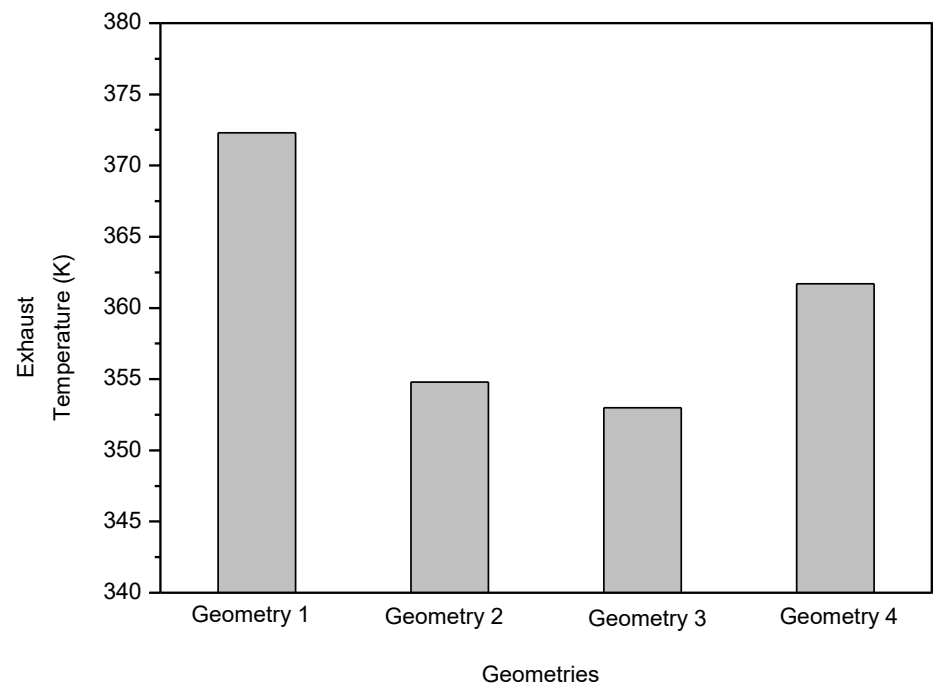

Fig. 6: Exhaust gas temperatures for different geometries.

\section{Conclusion}

In this study, flame structures, velocity distributions and exhaust gas temperatures were investigated numerically for four different boiler design of a liquid fuelled boiler. Keeping the outer dimensions constant at boiler design two parameters was investigated: the effect of the smoke tube diameter and numbers and the structure of the flame tube. As a CFD program Fluent software was used. Calculations were performed at two dimensional axisymmetric conditions. In all calculations, the standard k- $\varepsilon$ model was used for modeling the turbulent flow, the species transport model was used for modeling the combustion, and the pressurized swirl atomizer was used for modeling the injection. The calculations showed that decreasing the smoke tube diameters by doubling their numbers the exhaust gas temperatures decreased and the efficiency increased importantly. But increasing the smoke tube numbers from two to three the decrease in exhaust gas temperature is small and can be practically neglected. Also, narrowing the flame tube and changing the flow of the combustion gases in flame tube have positive effect on efficiency. As a result, Geometry 3 has the best performance among all of the designs, but Geometry 2 can be recommended as practicable and economical design.

\section{References}

[1] L. Cundari, L. N. Komariah, Novia, I. Maretha, L. Septiana, "Temperature Distribution of Biodiesel Blends Combustion in Boiler using CFD-Fluent," International Journal on Advanced Science Engineering Information Technology, vol. 6, no. 1, pp. 120-123, 2016.

[2] H. N. Mondal, S. Roy, "Numerical analysis of droplet combustion in a cylindrical furnace," Journal of Chemical Engineering, vol. 24, no. 1, 2006.

[3] N. L. Ing, M. N. M. Jaafar, M. S. A. Ishak, M. A. A. Arizal, "Spray characteristic of palm biofuel blends," International Journal of Mechanical and Materials Engineering, vol. 5, pp. 214-221, 2010.

[4] A. Saario, A. Rebola, P. J. Coelho, M. Costa, A. Oksanen, "Heavy fuel oil combustion in a cylindrical laboratory furnace: measurements and modelling," Fuel, vol. 84, pp. 359-369, 2005.

[5] D. Hu, "Comparison of numerical and experimental results of four liquid spray combustors," M. S. thesis, Dept. Mech. Eng., Louisiana State Univ., Baton Rouge, LA, 2002. 
[6] B. S. Hosseini, K. Bashirnezhad, A. R. Moghiman, Y. Kharzaii, N. Nikoofal, "Experimental comparison of combustion characteristic and pollutant emission of gas oil and biodiesel", International Journal of Mechanical and Materials Engineering, vol. 1, no. 1, 2010.

[7] Fluent 6.3, Fluent User's Guide, 2006. 